\title{
Cerebral vein thrombosis revealing Crohn's disease
}

\author{
Bouomrani $\mathrm{S}^{1,2 *}$, Rgaïeg $\mathrm{N}^{1,2}$, Guermazi $\mathrm{M}^{1,2}$ and Yahyaoui $\mathrm{S}^{1}$ \\ ${ }^{1}$ Department of Internal medicine, Military Hospital of Gabes, Tunisia \\ ${ }^{2}$ Sfax Faculty of Medicine, University of Sfax, Tunisia
}

\begin{abstract}
Introduction: Cerebral vein thrombosis (CVT) remains exceptional in inflammatory bowel disease (IBD), and cerebral venous sinus involvement in these diseases is qualified as "uncommon". They typically occur in patients with known and treated IBD but may exceptionally be the first manifestation of the disease. We report an original case of CVT of the right lateral sinus revealing $\mathrm{CD}$.

Case report: A 28-year-old woman with no significant pathological history was referred to our department for treatment and etiological assessment of isolated CVT of the right lateral sinus.

The somatic examination was without abnormalities. The basic bioassays showed a marked biological inflammatory syndrome. Screening for constitutional and acquired thrombophilias, autoimmune diseases, cancers, and hematological malignancies was negative. Colonoscopy revealed terminal ileitis with multiple aphthous ulcers. Histopathological examination of the ileal biopsies concluded to CD.

The patient was treated with systemic corticosteroids, mesalamine, and effective anticoagulation with favorable outcome. Cerebral MRI as well as colonoscopy at six months were without abnormalities, and no thrombotic recurrence has been noted for two years.

Conclusion: As rare as it is, this unusual complication of $\mathrm{CD}$ deserves to be known by all health practitioners to avoid diagnostic delays and improve the prognosis that is likely to be fatal.
\end{abstract}

\section{Introduction}

Recent data have demonstrated a particularly high risk of venous thromboembolic complications in patients with inflammatory bowel disease (IBD) compared to the general population $[1,2]$. The incidence of these complications is estimated at $1.3-7.5 \%$ according to the series [2] and seems to be slightly more common in ulcerative colitis than Crohn's disease (CD) [3,4].

The most common sites of venous thromboembolism during IBD are the deep veins of the legs, pulmonary arteries, portal vein, and mesenteric veins $[1,5]$.

However, cerebral vein thrombosis (CVT) remains exceptional in IBD $[1-3,6]$, and cerebral venous sinus involvement in these diseases is qualified as "uncommon" [2].

CVTs typically occur in patients with known and treated IBD $[1,2,6]$ but may exceptionally be the first manifestation of the disease [7]. We report the original case of CVT of the right lateral sinus revealing $\mathrm{CD}$.

\section{Case report}

A 28-year-old woman with no significant pathological history was referred to our department for exploration of isolated cerebral vein thrombosis.

For two days, the patient had had headache, visual blur, and vomiting unimproved by symptomatic treatment. She was examined by her family doctor who did not notice fever, meningeal signs, or rash. A cerebral tomodensitometry was requested and did not show any abnormality. Cerebral Magnetic Resonance Imaging (MRI) revealed thrombosis of the right lateral sinus (Figures 1, 2 and 3). The patient was referred to us for treatment and etiological assessment.

The somatic examination was without abnormalities. In particular, fever, peripheral lymphadenopathy, skin lesions, and organomegaly were not noted.

The patient also did not report recent trauma, drug, toxic, or oestroprogestative intake.

The basic bioassays just showed a marked biological inflammatory syndrome: a sedimentation rate at $90 \mathrm{~mm} / \mathrm{H} 1$, a C-reactive protein at $32 \mathrm{mg} / \mathrm{l}$, a polyclonal hypergammaglobulinemia at $24 \mathrm{~g} / \mathrm{l}$, and a normochromic normocytic anemia at $10.2 \mathrm{~g} / \mathrm{dl}$. Other biological parameters were within normal limits: leukocytes, platelets, blood glucose, transaminases, serum calcium, inonogram, lipid parameters, creatinine, thyroid stimulating hormone, lactic dehydrogenases, alkaline phosphatase, and muscle enzymes.

Screening for constitutional and acquired thrombophilias, autoimmune diseases, cancers, and hematological malignancies was negative: protein $\mathrm{C}, \mathrm{S}$, antithrombin III, mutation of factors $\mathrm{V}$ and II, anti-nuclear, anti-native DNA, anti-nucleosome, anti-phospholipid,

${ }^{\star}$ Correspondence to: Bouomrani S, Department of Internal medicine, Military Hospital of Gabes, Tunisia, Tel: +00216 98977555; E-mail: salembouomrani@yahoo.fr

Key words: cerebral vein thrombosis, crohn's disease, vein thrombosis, inflammatory bowel disease

Received: April 19, 2019; Accepted: April 26, 2019; Published: April 30, 2019 
and anti-neutrophil cytoplasm antibodies, abdominal ultrasonography, thoracoabdominopelvic CT, gastroscopy, myelogram, and tumor markers.

Colonoscopy revealed terminal ileitis with multiple aphthous ulcers. Histopathological examination of the ileal biopsies concluded to Crohn's disease. Subsequent investigations showed no extra-intestinal manifestations, and eliminated Behçet's disease, tuberculosis, and associated spondyloarthropathy.

The final diagnosis was active ileal CD revealed by CVT. The patient was treated with systemic corticosteroids, mesalamine, and effective anticoagulation with favorable outcome.

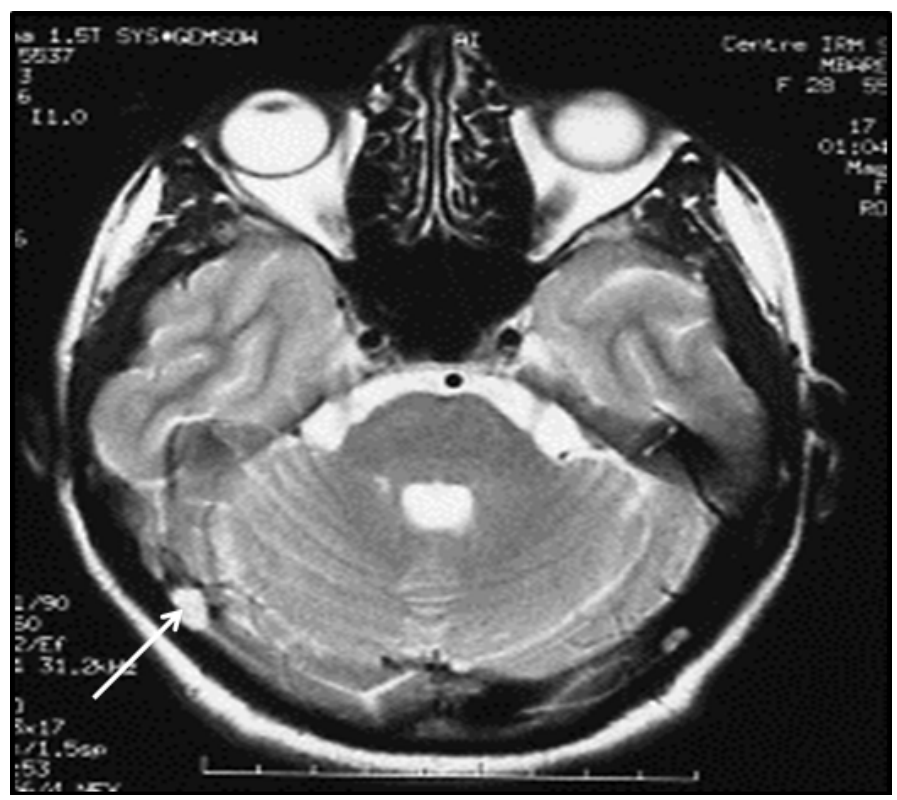

Figure 1. T2-weighted axial cerebral MRI: hyperintense image within the right latera sinus lumen (thrombus)

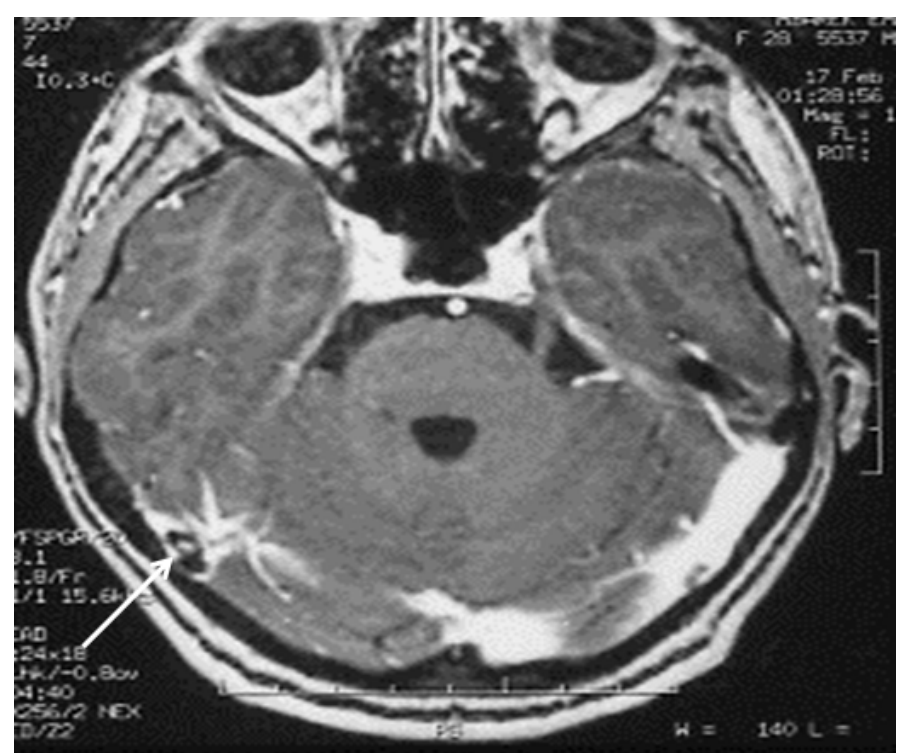

Figure 2. T1-weighted axial cerebral MRI with gadolinium injection: lacunary image within the right lateral sinus lumen (thombus)

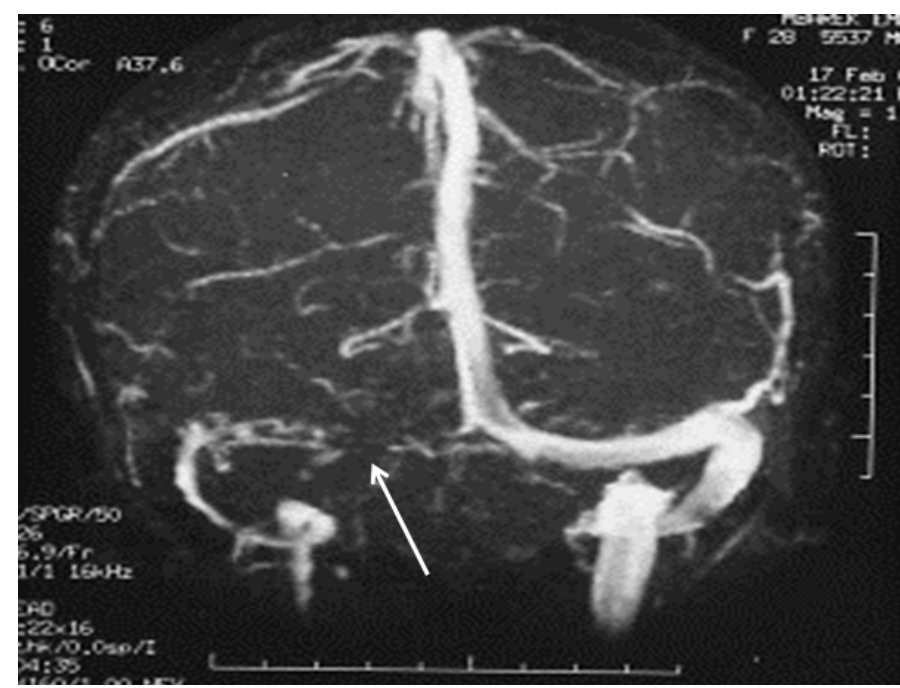

Figure 3. Venous angio-MR in posterior view: Absence of opacification of the right lateral sinus in its proximal portion

Cerebral MRI as well as colonoscopy at six months were without abnormalities, and no thrombotic recurrence has been noted for two years.

\section{Discussion}

CVT remains exceptional during CD and only a few sporadic cases have been reported in the world medical literature $[1,2,6]$. Similarly, CD is classically listed as "unusual" cause of CVT [8]; indeed, in the Cognate E et al series of 351 patients explored for CVT, only two had $\mathrm{CD}$ as the causal disease of this thrombosis (0.56\%) [7].

CVT associated with CD can occur at any age and even pediatric cases have been reported [9] and appears to be particularly common in highly active forms and during acute flares of the disease [1,2].

Several cerebral veins may be thrombosed in the same patient with CD (multiple CVT) [1,2], and recurrence is common despite effective treatment [5].

The pathophysiology of these thromboses associated with $\mathrm{CD}$ is multifactorial. It involved a genetic predisposition, a state of hypercoagulability characterizing $\mathrm{CD}$, and chronic inflammation $[2,6]$. The occurrence of these thromboses outside acute flares and during non-active forms of the disease, confirms the specific thrombogenic risk of $\mathrm{CD}[6]$.

MRI with angiographic sequences is the test of choice for the diagnosis of these CVTs. It is significantly more sensitive than cerebral computed tomography, which can remain normal in almost $20 \%$ of cases of CVT $[1,2,6,7]$.

Thrombotic risk should be considered in any patient with CD, particularly in the active forms of the disease and at the beginning of steroid treatment $[1,2]$. Preventive anticoagulation in these forms can prevent thromboembolic complications, including CVT that can be fatal $[1,3]$. Similarly, patient should be questioned about any possible digestive/intestinal signs, even minors, in front of any CVT that is not proven [7]. 


\section{Conclusion}

As rare as it is, this unusual complication of Crohn's disease deserves to be known by all health practitioners to avoid diagnostic delays and improve the prognosis that is likely to be fatal.

Our observation is distinguished by its inaugural character of the disease, which, to our knowledge, has not been reported in the cases identified in the world literature.

\section{Conflict of interest}

\section{None}

\section{References}

1. Cho YH, Chae MK, Cha JM, Lee JI, Joo KR, et al. (2016) Cerebral venous thrombosis in a patient with Crohn's disease. Intest Res 14: 96-101. [Crossref]

2. Ansari RS, Domfu FM, Felemban B, Mutair WH (2012) Cerebral venous sinus thrombosis in Crohn's disease. The empty delta sign. Neurosciences (Riyadh) 17: 61-3. [Crossref]
3. DeFilippis EM, Barfield E, Leifer D, Steinlauf A, Bosworth BP, et al. (2015) Cerebral venous thrombosis in inflammatory bowel disease. J Dig Dis 16: 104-108. [Crossref]

4. Kappelman MD, Horvath-Puho E, Sandler RS, Rubin DT, Ullman TA, et al. (2011) Thromboembolic risk among Danish children and adults with inflammatory bowel diseases: a population-based nationwide study. Gut 60: 937-43. [Crossref]

5. Papay P, Miehsler W, Tilg H, Petritsch W, Reinisch W, et al. (2013) Clinical presentation of venous thromboembolism in inflammatory bowel disease. J Crohns Colitis 7: 723-9. [Crossref]

6. Kim I, Min KH, Yeo M, Kim JS, Lee SH, et al. (2015) Unusual Case of Cerebral Venous Thrombosis in Patient with Crohn's Disease. Case Rep Neurol 7: 115-120. [Crossref]

7. Cognat E, Crassard I, Denier C, Vahedi K, Bousser MG (2011) Cerebral venous thrombosis in inflammatory bowel diseases: eight cases and literature review. Int $J$ Stroke 6: 487-92. [Crossref]

8. Khatri IA, AlKawi A, Ilyas A, Ilyas MS (2006) Unusual causes of cerebral venous thrombosis. J Pak Med Assoc 56: 501-506. [Crossref]

9. Rosen I, Berkovitz D, Soudack M, Ben Barak A, Brik R (2007) Cerebral vein thrombosis in a child with Crohn's disease. Isr Med Assoc J 9: 620-621. [Crossref]

Copyright: $@ 2019$ Bouomrani S. This is an open-access article distributed under the terms of the Creative Commons Attribution License, which permits unrestricted use, distribution, and reproduction in any medium, provided the original author and source are credited. 